\title{
Innovative Microreactors for Low-grade Feedstock Gasification
}

\author{
Said Samih, Sherif Farag and Jamal Chaouki \\ Additional information is available at the end of the chapter \\ http://dx.doi.org/10.5772/intechopen.74602
}

\begin{abstract}
The first fluidized bed thermogravimetric analyzer (FBTGA) has been developed. The proof of concept of the FBTGA has been carried out on the thermal decomposition of calcium hydroxide. The kinetics and modeling of coal pyrolysis and gasification were investigated in the FBTGA. The obtained activation energies for the individual gases that are produced from coal pyrolysis are 19 to $21 \%$ lower than those found for similar coals in the literature. This decrease in the activation energies is explained by a temperature gradient of 185 to $209^{\circ} \mathrm{C}$. For the CO shift reaction, the resulting activation energy is $46.6 \mathrm{kcal} /$ $\mathrm{mol}$, increasing by $20 \%$ from the one used in the literature. The second reactor presented in this work is a TGA powered by electromagnetic irradiation. As an application for this reactor, a novel kinetic model based on a dual attempt to predict not only the yield but also the composition of bio-oil is presented. The validation of the developed models demonstrated an excellent capability of predicting the yield and quality of the produced oil. The third reactor is a saddle reactor, which consists of two V-shaped pairs of arms and minimizes the impact of the heat and mass transfer limitation on chemical reactions.
\end{abstract}

Keywords: fluidized bed TGA, microwave TGA, saddle reactor, kinetics, gas-solid reactions

\section{Introduction}

Due to environmental constraints and a lack of access to natural resources, the feedstocks of several industrial sectors are changing, which is one reason why many industrial applications use new fuel sources and blends of feedstocks, including biomass, lignin, coal, and petcoke. The intrinsic variability in feedstock makes it challenging to design, operate, and optimize a chemical process, where detailed information regarding hydrodynamics, transport phenomena, and reaction kinetics among other subjects, is essential. 
The gasification of coal technology also faces many issues, including low efficiency, the presence of tar, high capital, and operating costs. Furthermore, power efficiency of gasification decreases by the presence of ash in coal, which is also a major constituent of air pollutants.

One of the main problems in a low-grade coal gasification process is the formation of deposits, which can prevent gas flow and heat transfer, thereby obstructing the operation of the process. High-process efficiency could be theoretically and thermodynamically obtained with low-rank coal by using better solid-gas contacting systems and catalysts.

The common problem of all gasification technologies is building an appropriate apparatus to develop reliable kinetics. Since the gasifier is at the heart of a coal gasification plant, the overall performance of the plant can be successfully analyzed based on the reliability of the reactor modeling. The design of a gasifier is based on the reliability of the kinetics used for this purpose.

During the last few decades, a limited effort has been made to investigate these topics when a complex feedstock is being processed. In addition, a few microreactors have been invented to overcome the issues and limitations associated with the conventional instruments used to investigate the abovementioned topics. Microreactors are used in the field of chemical engineering for their advantages over reactors of traditional sizes. The microreactors are more powerful due to their small size so the gravitational force can be neglected. The surface forces will therefore be greater and the mass and energy transfer to the reactor will be higher.

Different experimental techniques can be applied to help define some reactions, for instance, solid fuel pyrolysis, combustion, gasification and thermal decomposition of polymers. Thermogravimetric analysis, differential thermal analysis, and differential scanning calorimetry are three experimental techniques used to determine the kinetics and the mechanism of gas-solid reactions that are thermally activated. There are some limitations with the thermogravimetric technique due to non-uniform temperatures, non-homogeneity of the distribution of gas-solid and solid-solid materials, low heating rates, not enough solid samples to represent the homogeneity of it, and the bulk, interparticle, and intraparticle diffusion control. This led to the invention of the first fluidized bed thermogravimetric analyzer that has the potential to decrease and eliminate these limitations $[1,4]$.

One of the advantages of the FBTGA due to fluidization is good mixing for a better distribution of solid and gas particles. It is therefore possible using the fluidized bed reaction chamber to achieve uniformity in the sample temperature, eliminate bulk and interparticle diffusion controls, have an acceptable quantity of solid sample, and obtain a higher heating rate. The main benefit is the new FBTGA that can be used to test and define catalytic gas-solid reactions on a smaller scale to gain a better overall view on an industrial scale.

The second novel system presented in this work is a TGA powered by microwave heating (MWH). The dominant mechanism of $\mathrm{MWH}$, which relies on the direct volumetric energy conversion within the irradiated material, has established $\mathrm{MWH}$ in a significant number of industrial applications. Superseding the superficial heat transfer of conventional heating $(\mathrm{CH})$ with that of $\mathrm{MWH}$ avoids most of the problems associated with $\mathrm{CH}$, the most paramount being the temperature gradient inside and outside the heated materials that prompt 
the undesirable secondary reactions. Based on the dielectric properties of the irradiated materials, MWH can dramatically diminish operating costs and the potential of a thermal hazard since it only interacts with particular types of materials. This aspect would lead to producing materials with a novel microstructure and/or initiate reactions that cannot be initiated when $\mathrm{CH}$ is applied. Also, it can perform the existing reactions under conditions that are entirely different from that of $\mathrm{CH}$. The main reason behind these unique merits is the ability to concentrate the generated heat energy at a particular component among others, which might affect the reaction kinetics. The high precision and safety of the microwave heating technology offer a greater level of control that, consequently, presides over the target end in a delegated manner. As microwave irradiation is easily and rapidly initiated and terminated, such a mechanism would lead to reducing the undesirable intermediate thermal steps and, in turn, enhance the production rate. Indeed, these unique advantages and others help in the fundamental understanding of the energy conversion mechanism of $\mathrm{MWH}$ and how it impacts the chemical reaction engineering, especially when a non-conventional feedstock is processed.

The main objective of this chapter is to demonstrate two of the up-to-date systems developed for a better understanding of the chemical reactions behind the processing of complex feedstocks. To do so, the abundance and characteristics of low-grade feedstocks are debated. The common problems associated with the processing of such non-conventional materials are presented. The novel microreactors that have recently been developed in academia, including the fluidized bed thermogravimetric analyzer and the microwave thermogravimetric analyzer that was developed in the PEARL group, are elucidated. PEARL stands for process engineering advanced research lab [5].

\section{Experiments}

\subsection{Material}

\subsubsection{Experiments in the fluidized bed TGA}

The materials that were used for the fluidized bed TGA are the Western Canadian lignite coal (WLC) and ash free coal. The ash free coal was produced by the Department of Chemical and Materials Engineering, University of Alberta, Canada. It was produced by solvent extraction [2, $3,6,7]$. The proximate and the ultimate analyses are presented in Table 1 . Furthermore, $\mathrm{K}_{2} \mathrm{TiO}_{3}$ was the commercial catalyst that was used for the catalytic ash free coal gasification experiments.

\subsubsection{Materials for the experiments in the microwave thermogravimetric analyzer}

The virgin material processed in the developed MW-TGA was softwood kraft lignin that precipitated from a Canadian kraft mill using the LignoForce System ${ }^{\mathrm{TM}}$, a patent pending process. The CHNS of lignin are $\mathrm{C}=63.27 \%, \mathrm{H}=5.79 \%, \mathrm{~N}=0.07 \%$, and $\mathrm{S}=1.56 \%$, and the approximate analyses are fixed: carbon $=37 \%$, volatiles $=62 \%$, and $a s h=1 \%$. Further analysis of the processed material can be found in the references [8-12]. 


\begin{tabular}{lll}
\hline & Canadian lignite coal & Ash free coal \\
\hline Proximate analysis (wt. \% a.r.) & 34.3 & 46.7 \\
Fixed carbon & 39.3 & 53.2 \\
Volatile matter & 15.4 & Trace \\
Ash & 11.1 & Trace \\
Moisture & & \\
& & \\
Ultimate analysis (wt. \%) & & 88.9 \\
C & 57.2 & 5.1 \\
H & 4.3 & 1.5 \\
N & 1.20 & 24.9 \\
O & 21.1 & 0.0 \\
S & 0.1 & \\
a.r. as received & & \\
\hline
\end{tabular}

Table 1. Analysis of the Western Canadian lignite coal [2].

\subsection{Apparatus description}

\subsubsection{Fluidized bed TGA}

A schematic of the first microreactor presented in this book chapter is shown in Figure 1. This apparatus represents the first fluidized bed thermogravimetric analyzer (FB-TGA) in the world. It comprises a quartz reactor that can operate at temperatures from 25 to $1200^{\circ} \mathrm{C}$, furnace and measuring instruments, such as thermocouples, two mass flow controllers, pressure transducers and load cell. The FBTGA is connected to a data acquisition system. The fluidization is set to the minimum rate for any temperature using specific software. The quartz operates at atmospheric pressure with a wide range of solid samples, with a maximum amount of $50 \mathrm{~g}$.

\subsubsection{Microwave thermogravimetric analyzer}

Two significant modifications were performed to make a traditional microwave oven work as a TGA. To accurately measure the weight loss of the payload during exposure to microwaves, the carrier reactor was directly connected to a scale fixed on the top of the oven through two opposing side-holes, as shown in Figure 2. To measure the transient mean temperature of the payload during the exposure to microwaves, an innovative thermometer called an "air-thermometer" was designed and made. That thermometer's theory is mainly based on the direct relationship between the pressure and temperature of a constant volume of gas. As soon as the temperature of the thermometer probe increases, the pressure of the gas that is inside the probe increases as well. The measured increase in the gas pressure is, then, translated to find the temperature of the payload. It is worth mentioning that the thermometer probe is made of 


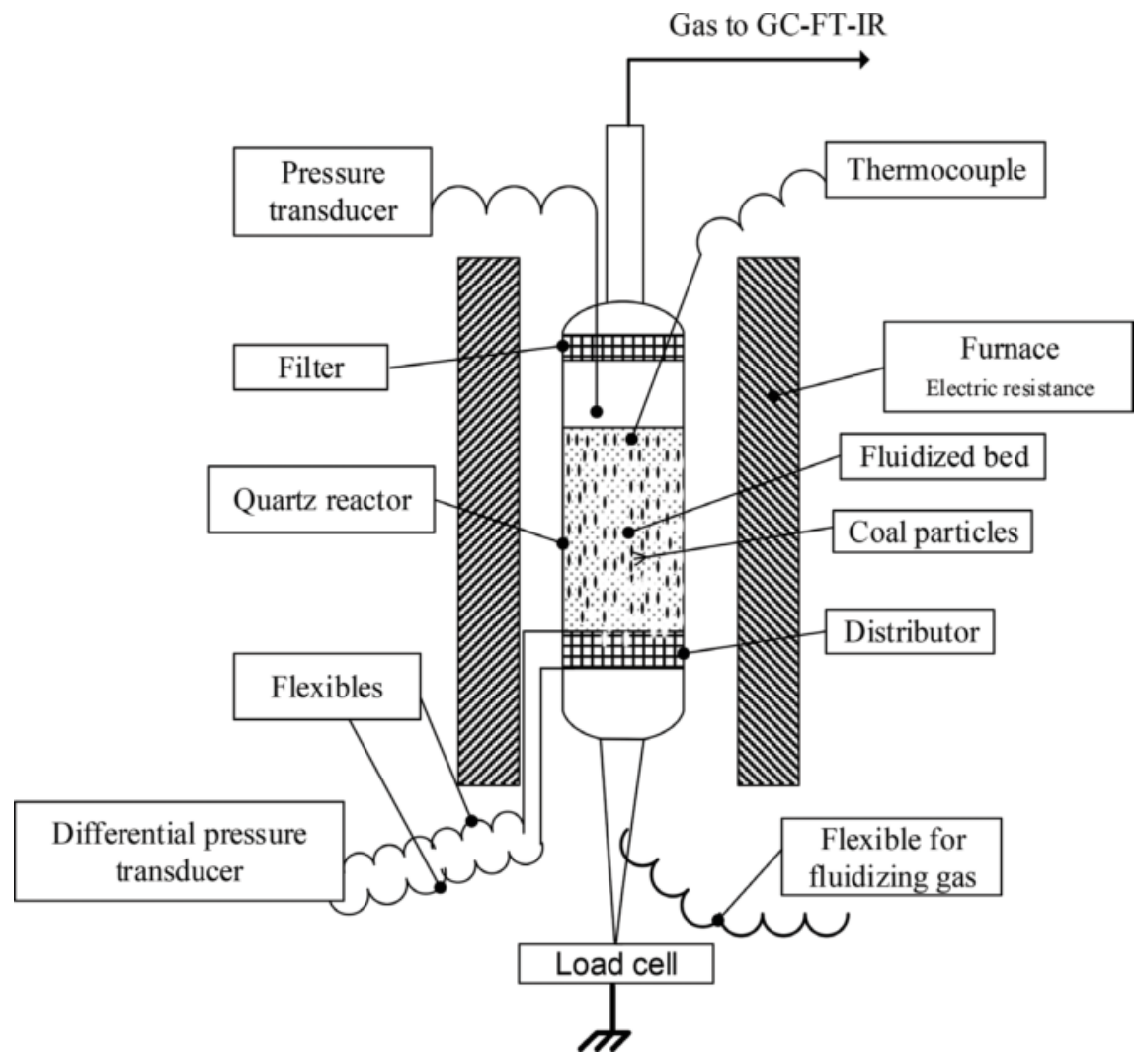

Figure 1. Fluidized bed TGA. Reproduced from reference [1].

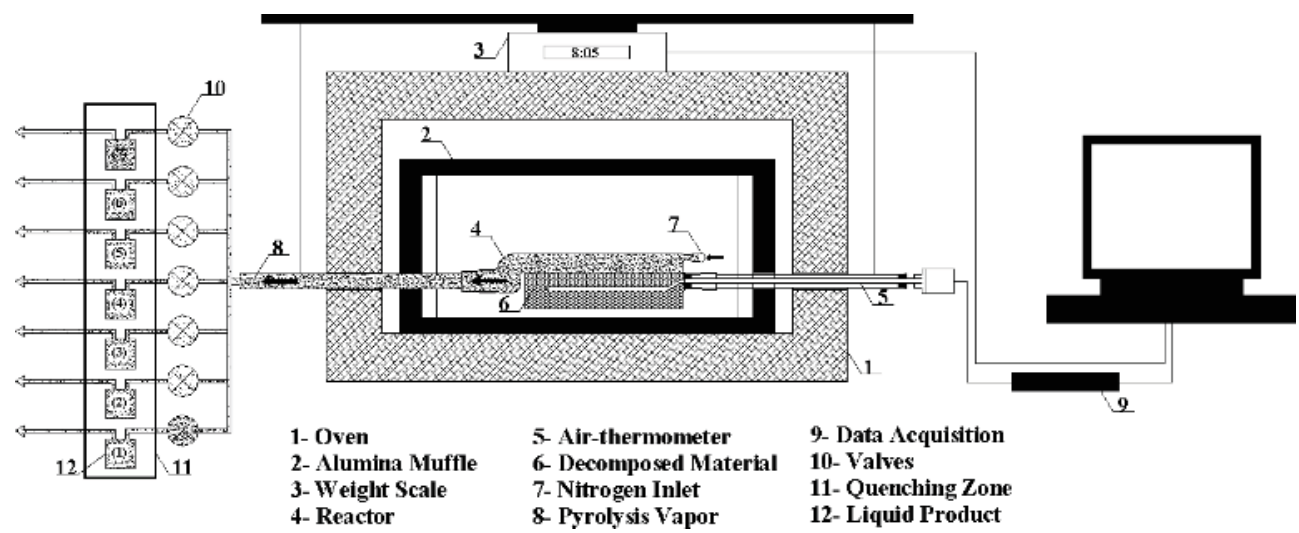

Figure 2. Microwave thermogravimetric analyzer. 
quartz and the working gas is air. This means that almost no interactions between the applied electromagnetic waves and the materials mentioned above have taken place. This aspect ensures that the innovated thermometer does not suffer from the drawbacks of traditional thermometers. A manifold that consists of seven ports is connected at the outlet of the reactor to enable splitting the gas/vapor product at different times/temperatures for kinetics and other purposes. Farag and his co-authors have called the developed system the MW-TGA, which, at the time, was the first MW-TGA developed in the literature. For further details, kindly refer to $[9,10,13,14]$.

\subsubsection{Saddle reactor}

In the chemical reaction where a gas phase is one of the leading products, using a fluidized gas to overcome the heat and mass transfer limitations creates an issue. This issue is mainly related to the dilution of the produced gas. To overcome this problem, a novel reactor-called "saddle reactor" - has been designed and built in PEARL labs. As shown in Figure 3, the saddle reactor consists of two V-shaped pairs of arms connected at their bottoms by a small chamber. One of these two V-shaped is twisted by $90^{\circ}$; it is the optimum angle for the best mixing efficiencywhich has been proofed in our previous publications. A set of heating elements is distributed in each arm to reach the needed temperature of performing the reaction. The power of those heaters was calculated and chosen to provide the heat energy required to achieve a particular end. Four built-in thermocouples are employed to control the input power to the heating elements and avoid reaching their melting points. A fifth thermocouple is fixed in the middle of the chamber that combines all the heating elements. This thermocouple controls the whole system based on the temperature of the payload. This means that the five measured temperatures are used to control the heating power of the system. The outlet of the saddle reactor is connected to two analytical techniques, GC and FTIR, to analyze the gas product.

\subsection{Experimental procedures}

\subsubsection{Coal pyrolysis and gasification in the FB-TGA: the first application}

The experiments for this first application of the FB-TGA were carried out in three steps: coal pyrolysis, partial oxidation of char, and coal gasification. The pyrolysis was performed in a nitrogen atmosphere. The heating rate was $40^{\circ} \mathrm{C} / \mathrm{min}$ up to a maximum temperature of $700^{\circ} \mathrm{C}$. The reactional system stabilized at $700^{\circ} \mathrm{C}$ for more than three hours. Novel kinetic parameters were developed for coal pyrolysis reactions from the collected data during the whole experiment time. During the second step, a specific gas mix of 5\% oxygen-balance nitrogen was used to partially oxidize the produced char from the first step. The same heating rate and program were used. The experimental data were collected and used to derive kinetic parameters for the partial oxidation of the char. The third step in the FB-TGA was the coal gasification. During this third step, two different experiments were separately carried out under different conditions. The first one was at $650^{\circ} \mathrm{C}$, while the second one was at $750^{\circ} \mathrm{C}$. The two reactions were repeated three times. The method of collecting data was the same and the heating method was the same as the one that was used for the first two steps. The product gases, such as $\mathrm{CO}, \mathrm{CO}_{2^{\prime}}$ $\mathrm{H}_{2}, \mathrm{CH}_{4}$ and $\mathrm{H}_{2} \mathrm{O}$, were measured by a system of gas chromatography (GC)/Fourier-transform 
infrared spectroscopy (FT-IR). For the three steps, the condensed tar at the exit of the reactor was burned off at $750^{\circ} \mathrm{C}$.

\subsubsection{Catalytic ash free coal gasification in FB-TGA: the second application}

For this second application, about $5 \mathrm{~g}$ of lignite coal and ash free coals $>500 \mu \mathrm{m}$ and $<600 \mu \mathrm{m}$ in size were fluidized with $40 \mathrm{~g}$ of olivine sand, $>180 \mu \mathrm{m}$ and $<212 \mu \mathrm{m}$ in size. The experiments of coal gasification were carried out in a gas mixture of $5 \%$ oxygen-balance nitrogen $\left(\mathrm{N}_{2}\right)$, whereas those for ash free coal gasification were established in a gas mixture of $3 \%$ oxygen-balance nitrogen. The heating rate was $40^{\circ} \mathrm{C} / \mathrm{min}$ and the particle density for the olivine sand was $3290 \mathrm{~kg} \cdot \mathrm{m}^{-3}$. The gas flow rate was changed, based on the strategy developed for the fluidized bed TGA, depending on the temperature to maintain the bed at the minimum fluidization regime [1].

To test the stability of the catalyst $\mathrm{K}_{2} \mathrm{TiO}_{3^{\prime}} 20 \mathrm{~g}$ of the commercial catalyst was fluidized and heated up to $800{ }^{\circ} \mathrm{C}$ under air atmosphere for $5 \mathrm{~h}$. The results from the weight loss measurement and gas analysis demonstrated and confirmed that the commercial catalyst was stable. In all of the experiments, the $\mathrm{K} / \mathrm{C}$ weight ratio was $10 \%$, where $\mathrm{K}$ and $\mathrm{C}$ represent the amount of $\mathrm{K}$ and $\mathrm{C}$ that are contained in $\mathrm{K}_{2} \mathrm{TiO}_{3}$ and coal respectively.

\subsubsection{Microwave thermogravimetric analyzer (MW-TGA)}

Strategic procedures were performed to enable investigating the product yield and composition obtained from the microwave thermal cracking of lignin. The freezing zone that was used to collect the liquid product was kept at $-18^{\circ} \mathrm{C}$ and the entire tubing barrier to the condensation system was kept at $200^{\circ} \mathrm{C}$ to prevent any condensation before the freezing zone. Then, the reactor was filled with the raw material and connected as shown in Figure 2. Subsequently, the signal cables and the air thermometer were installed, and an inert environment was created by purging the system with $\mathrm{N}_{2}$.

When the reaction started, all the valves of the product manifold were closed, except one that was used for collecting the product. Afterward, at a certain temperature/time, the opened port was switched off, and the closed one was switched on to start receiving the product during another interval temperature/time. Once the reaction was eventually completed, the obtained liquids and the solid product were cold to the ambient temperature. The liquid product was separated into the oil phase, which has the most organic chemicals, and the aqueous phase, which is lower in density than the oil phase and mostly water and sent for analysis.

\section{Results and discussion}

\subsection{Proof of the concept of the fluidized bed TGA}

The proof of the concept of the fluidized bed TGA was carried out with the thermal decomposition of the calcium hydroxide. The results for the fluidized bed and conventional TGAs are shown in Figure 3. For the conventional TGA, three different amounts of calcium hydroxide $(10,25$, and $140 \mathrm{mg}$ ) were tested, while $4 \mathrm{~g}$ of calcium hydroxide were used in the FB-TGA. 


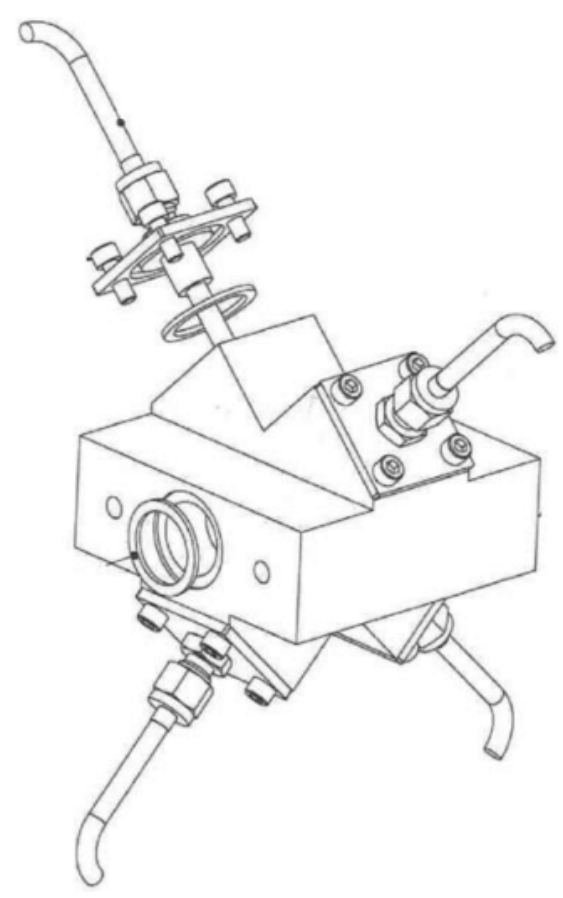

Figure 3. Saddle reactor.

For the first temperature interval, the results with $25 \mathrm{mg}$ from the conventional TGA were similar to the ones for the FB-TGA with $4 \mathrm{~g}$ of calcium hydroxide. The conventional TGA results for 10 and $25 \mathrm{mg}$ are similar, but they are different from those obtained for $140 \mathrm{mg}$. Two different parts can be distinguished in Figure 4. For 10 and $25 \mathrm{mg}$, the first part can be defined from $370^{\circ} \mathrm{C}$ to $470^{\circ} \mathrm{C}$, whereas this first part is from $395^{\circ} \mathrm{C}$ to $565^{\circ} \mathrm{C}$ for $140 \mathrm{mg}$ [1].

For the first part, the heat transfer limitation and/or the temperature gradient are responsible for the difference between the results obtained for 10, 25, and $140 \mathrm{mg}$. The intraparticle and the external diffusions of the produced water through a small layer of $\mathrm{CaO}$ that was formed around the $\mathrm{Ca}(\mathrm{OH})_{2}$ became the rate-controlling step of the thermal decomposition during the second step [1].

Only for the first step, the results for $25 \mathrm{mg}$ of $\mathrm{Ca}(\mathrm{OH})_{2}$ in the conventional TGA agree with those for $4 \mathrm{~g}$ in the fluidized bed TGA. Indeed, the thermal decomposition of $\mathrm{Ca}(\mathrm{OH})_{2}$ in the FB-TGA was carried out in one stage, from $360^{\circ} \mathrm{C}$ to $540^{\circ} \mathrm{C}$. Thus, a better heat transfer and mass transfer of water vapor was obtained with the use of the FB-TGA and no diffusion control was observed.

\subsection{Coal pyrolysis and gasification in the fluidized bed TGA}

The experiments of coal pyrolysis and gasification were carried out in the fluidized bed TGA. These experiments were used to derive novel kinetic parameters from the fluidized bed TGA. 


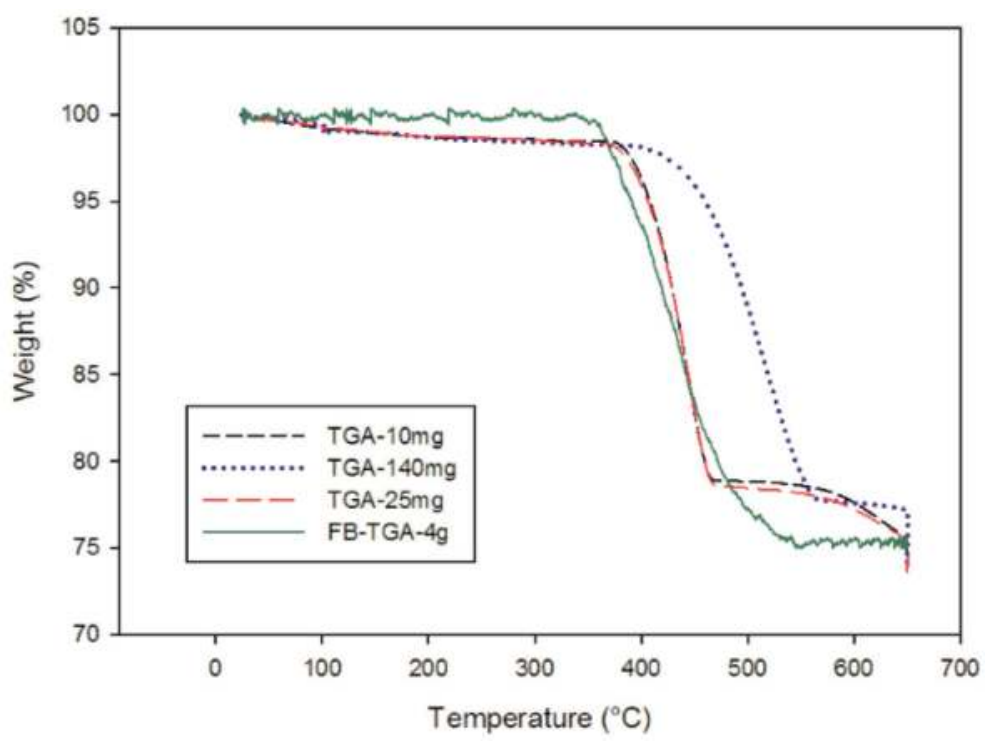

Figure 4. $\mathrm{Ca}(\mathrm{OH})_{2}$ decomposition: comparison between conventional and fluidized bed TGAs. Reproduced from reference [1].

The weight loss measurement and the quantity of gas produced showed general agreement, for both coal pyrolysis and gasification results.

Due to a $170-209$ oC temperature gradient, the obtained values of some activation energies are lower or higher than what was found in the literature. The obtained activation energy for the CO shift reaction was $195.0 \mathrm{~kJ} / \mathrm{mol}$. This value is $20 \%$ higher than the one in the literature. The obtained activation energies for coal pyrolysis reactions were 19-21\% lower than the ones obtained in the literature for similar coals [2]. These new results confirm that there was a measurement error of the temperature in certain past studies. Such measurement error means that for the past studies, the reaction chamber temperature was not the one that is used to find kinetic parameters. Thus, there is a temperature gradient between the measured temperature by the thermocouple of the conventional thermogravimetric analyzer and the real one of the reaction. Such increase of $19-21 \%$ of the activation energy is the equivalent of $185-209^{\circ} \mathrm{C}$ temperature gradient of similar relatively exothermic reactions $[2,4,15]$. Finally, the results obtained were as expected and confirmed that the FB-TGA provides reliable kinetic parameters. More discussion and results are shown in our previous work $[3,4]$.

\subsection{Catalytic ash-free coal gasification in a fluidized bed TGA}

The second experiment that was carried out on the FB-TGA is about the catalytic ash free coal gasification. In this work, the effect of the catalyst on ash free coal gasification is included. A comparison of the total product gas yield and the weight loss is represented in Figure 5. 
The two experimental results are in global agreement, and the slight difference is due to the produced tar from ash coal experiments.

A comparison of the carbon conversion results of coal, ash free coal and catalyst with ash free coal is illustrated in Figure 6. CatAFC, AFC, and coal, stand for the catalyst with ash free coal, ash free coal and coal gasification, respectively. The lowest carbon conversion is obtained from ash free coal for temperatures lower than $730^{\circ} \mathrm{C}$, after which the coal

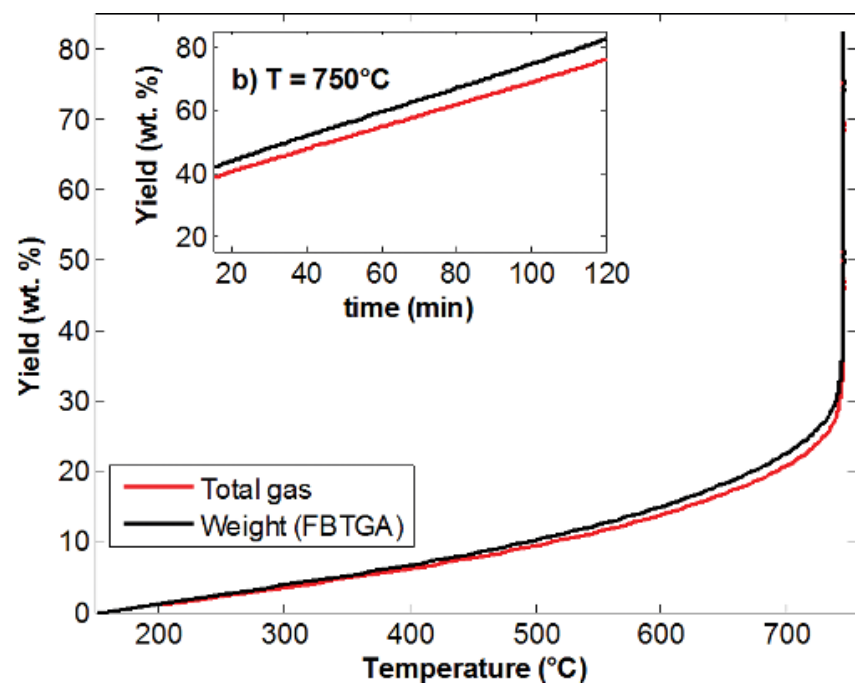

Figure 5. Catalytic ash free coal gasification in a fluidized bed TGA. Reproduced from reference [2].

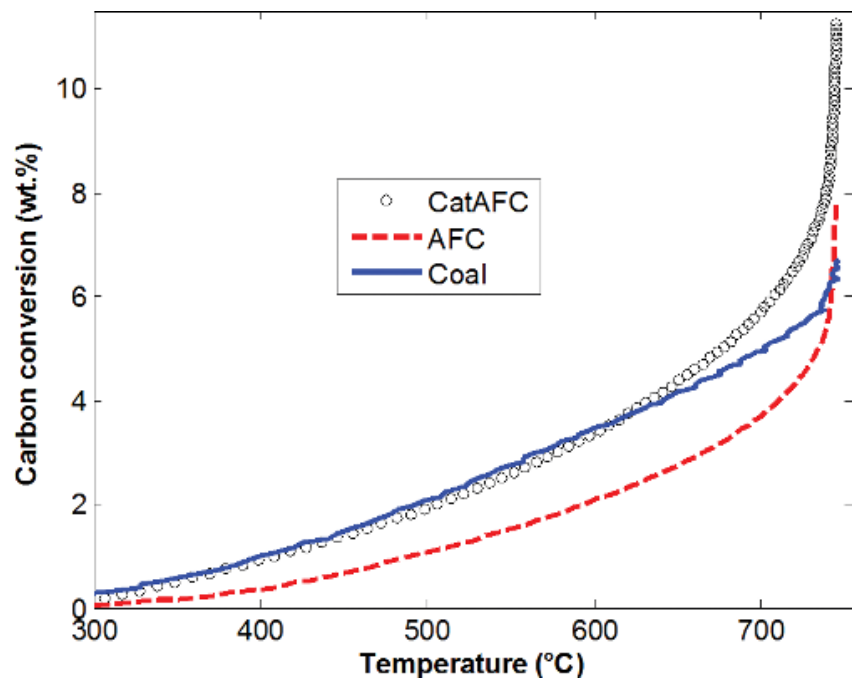

Figure 6. Temperature effect on carbon conversion. Reproduced from reference [2]. 
gasification had the lowest carbon conversion result. Thus, coal beneficiation has a negative affect on carbon conversion. Nevertheless, at $700^{\circ} \mathrm{C}$, there is an increase of carbon conversion by 15.3 and $52.6 \%$, for coal and ash free gasification. These values increased to 44.5 and $69.1 \%$ at $750^{\circ} \mathrm{C}[2]$.

Moreover, novel kinetic parameters are obtained form the FB-TGA experimental results for the reactions of partial oxidation, gas-water shift, and methane reforming. For char gasification, the results are similar to those found in literature [16]. For the gas-water shift and methane reforming reactions, the obtained activation energies were 56.5 and $77 \mathrm{~kJ} / \mathrm{mol}$, respectively. Compared to the values found in literature, these results are significantly lower. The lowest activation energy for the water-gas shift reaction was $70 \mathrm{~kJ} / \mathrm{mol}[2,17-19]$, which is 1.24 times higher than the one obtained in the fluidized bed TGA.

The lowest activation energy found in literature for the methane reforming reaction is $85 \mathrm{~kJ} /$ mol $[2,18]$, which is $10 \%$ higher than the one obtained with the fluidized bed TGA.

The values of the activation energies of the $\mathrm{CO}$ shift and the methane reforming reactions decreased by $56 \%$ and $33 \%$, respectively, by using the catalyst. This catalyst was applied on other reactions in the literature and the activation energy was decreased by 43 to $75 \%$ [2, 20]. More results and discussions are given in our previous article [2].

\subsection{Microwave thermogravimetric analyzer}

Farag and his co-authors have employed the obtained experimental data from the developed MW-TGA, following the method presented in Section 2.3.3, to carry out a kinetic study based on the lumped approach. The established model in their work takes into consideration the chemical composition of the oil and aqueous products that are obtained from the microwave pyrolysis of lignin. As shown later, it considers that the virgin material converts into seven main products: remaining solid, phenolics, aromatic single ring and non-phenols (ASR-Non-Ph), aliphatics, heavy molecular weight compounds (HMWCs), water, and noncondensable gas, as shown later. The kinetic model demonstrated in Eq. (1) was used to estimate the kinetic parameters, activation energy, pre-exponential factor, and reaction order associated with every reaction toward producing these seven products.

$$
\begin{aligned}
& \text { Lignin Pemaining Solid }
\end{aligned}
$$

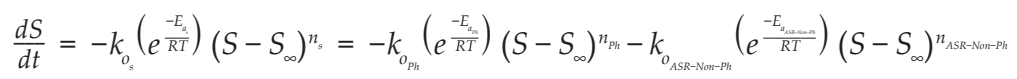

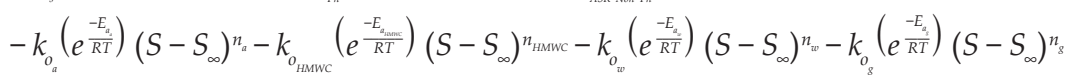


In Eq. (1), $\mathrm{k}_{\mathrm{o}}$ is the pre-exponential factor [ time $\left.^{-1}\right], \mathrm{E}_{\mathrm{a}}$ is the apparent activation energy $[\mathrm{J} / \mathrm{mol} \mathrm{K}], \mathrm{T}$ is the reaction temperature $[\mathrm{K}]$, and $\mathrm{R}$ is the universal gas constant $[\mathrm{J} / \mathrm{mol} \mathrm{K}]$. The subscripts s, ph, ASR-Non-ph, a, HMWC, g, and w refer to solid, phenolic, aromatic single ring and non-phenolic, aliphatic, heavy molecular weight compound, gas and water products, respectively. Figure 7
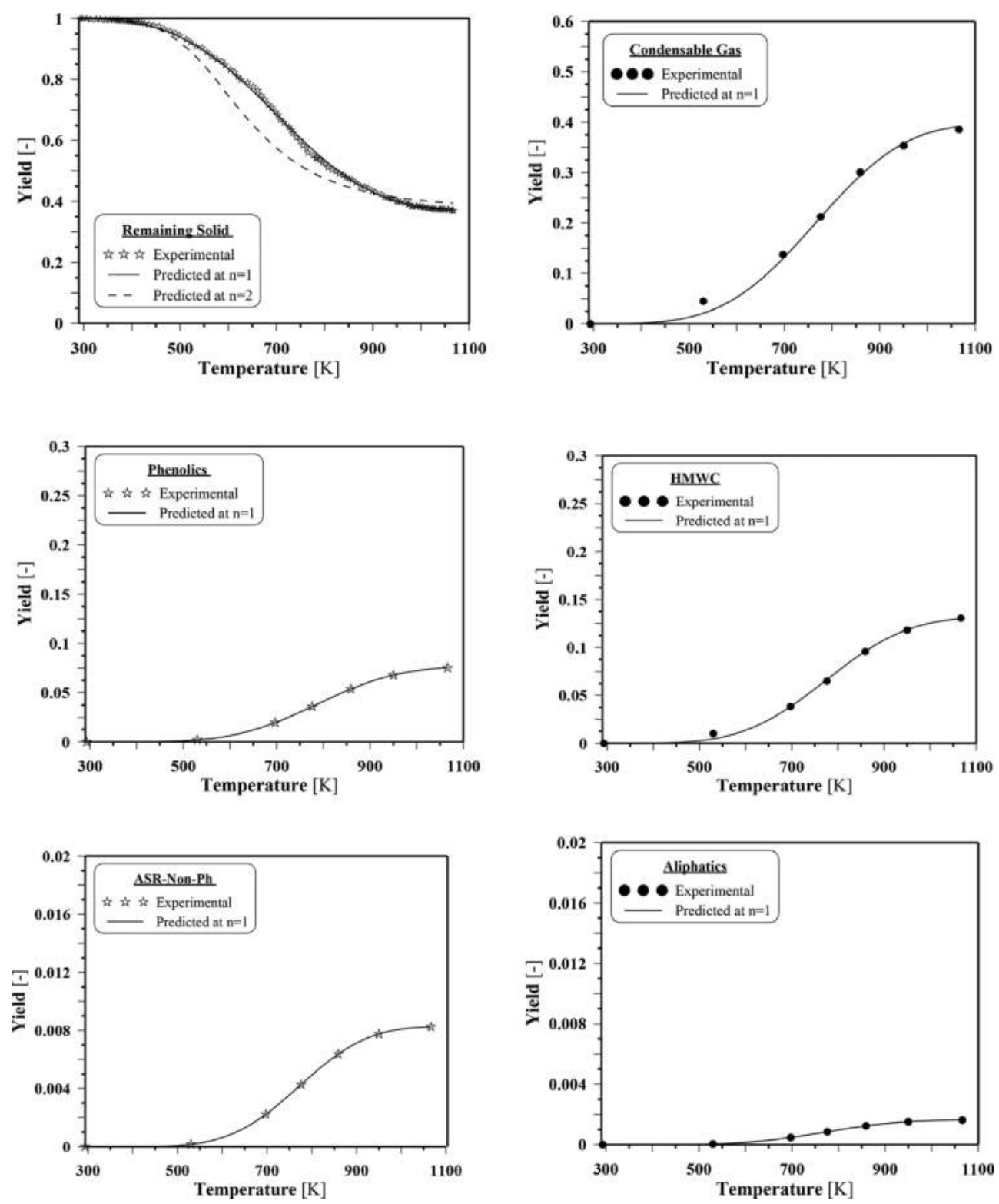

Figure 7. Experimental and predicted yields of lignin pyrolysis products. Reprinted with a permission form [5]. 
demonstrates the experimental and predicted yield of these products, except water, which can be calculated by subtracting the summation of these products from unity. Table 2 shows that the estimated kinetic parameters of each single reaction lead to the production of each of these products. For the full details regarding how these parameters were determined, kindly refer to [10].

Farag et al. believe that up to $725 \mathrm{~K}$ the condensable gas yield is slightly lower than that of the non-condensable gas, which could be the result of the swift split in lignin-side aliphatic hydroxyl groups [10]. Beyond $725 \mathrm{~K}$, the total liquid yield continues increasing because of the decomposition of strong chemical bonds in the lignin network. Based on the estimated kinetic parameters, the reaction rate of the liquid products is lower than that of the solid product. The authors have claimed that the low secondary reactions under these conditions might be the reason for this result. The non-condensable gas product is mostly produced from the cracking of lignin-side chains, and the liquid product is produced from the breakdown of bonds between lignin aromatic rings. Therefore, the estimated activation energy of the non-condensable gas is lower than that of all oil products. Since the structure of the decomposed material's network is totally poly-aromatics, the reaction rate to produce phenolics and HMWC groups is much higher than that of ASR-Non-Ph. Accordingly, the estimated activation energy of aliphatics is greater than that of the other groups. The authors also think about the impact of microwave heating to decrease the probability of a secondary reaction when producing aliphatics.

In the scientific literature, an apparent contradiction to the interpretation of the influence of electromagnetic irradiation on reaction kinetics has been documented. Wang et al. 2013, Li et al. [26], Fukushima et al. 2013, Adnadjevic and Jovanovic [25], Sun et al. [22], Jovanović 2012, and a few other research groups believe that the reaction activation energy decreases under microwave irradiation [21-28]. On the other hand, Mazo et al. [28] and Yadav and Borkar [27] have reported that $E_{a}$ is the same in both cases, $\mathrm{MWH}$ and $\mathrm{CH}$ [13, 29-31]. It is well known that the wavelength of microwaves is significantly longer than the intermolecular distance of the target, which ideally doubles the impact of $\mathrm{MWH}$ on the activation energy. However, this does not reject the probability of producing some intermediates that could

\begin{tabular}{llll}
\hline Product & ko $\left[\mathrm{min}^{-1}\right]$ & Ea [kJ/mol] & $\mathbf{n}$ \\
\hline Remaining solid & 7 & 19 & 1 \\
Water & 9 & 27 & 1 \\
Phenolics & 21 & 38 & 1 \\
HMWC & 22 & 35 & 1 \\
ASR-Non-Ph & 1 & 40 & 1 \\
Aliphatics & 20 & 47 & 1 \\
Condensable gas & 22 & 29 & 1 \\
Non-condensable gas & 6 & 22 & 1 \\
\hline
\end{tabular}

Table 2. The estimated kinetic parameters of the Farag et al. [5] model. 


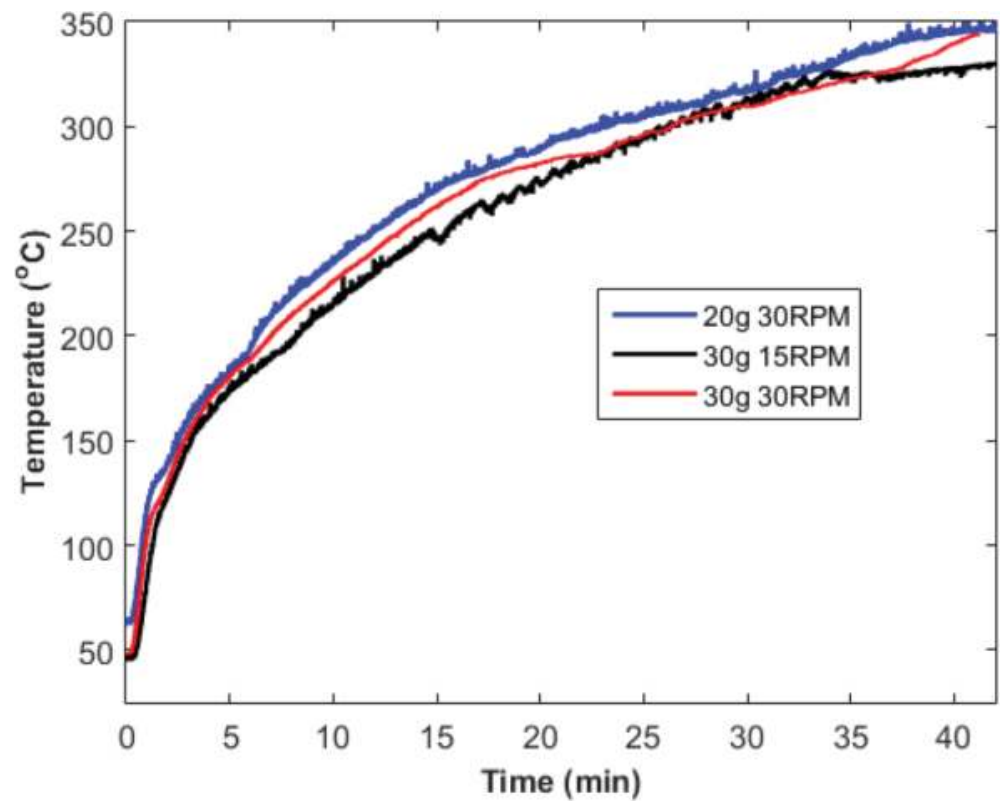

Figure 8. Effect of the speed mixing on the temperature profile in the saddle reactor.

have different behaviors than that of the starting material which would impact the activation energy. In such cases, the dielectric properties of the produced intermediates should be measured and investigated to understand the potential of having hot spots that affect the reaction kinetics locally $[14,32,33]$. Therefore, further investigations are required to discover the fact behind the reported effects on the activation energy and other reaction kinetic parameters.

\subsection{Saddle reactor}

As explained previously, the saddle reactor is mainly used to avoid the dilution of the product gas. Indeed, the solid sample can be very well mixed in the saddle reaction chamber without using a gas mixing agent. To prove this concept, different masses of silica sand - from 20 to $30 \mathrm{~g}$ - were mixed and heated up to $350^{\circ} \mathrm{C}$ in the reactor. The results shown in Figure 8 are for different mixing speeds, ranging from 15 to 30 RPM. The similar temperature profiles confirm the good mixing in the developed reactor.

\section{Conclusion}

New microreactors for the gasification of low-grade feedstock have been developed. The fluidized bed TGA was applied to the coal and ash-free coal gasification. New values of activation energies are obtained. The values for coal pyrolysis are from 34.7 to $59.8 \mathrm{kcal} / \mathrm{mol}$, whereas the one for the $\mathrm{CO}$ shift reaction is $46.6 \mathrm{kcal} / \mathrm{mol}$. The use of the potassium catalyst is allowed to reduce the activation energies of the $\mathrm{CO}$ shift and the methane-reforming reactions 
by 56 and 33\%, respectively. A novel microwave-TGA equipped with an innovated air thermometer and a product manifold was built. The developed system was used to predict the product yield and the bio-oil composition from pyrolysis of kraft lignin using a lumping approach. The experimental data were employed to estimate the kinetic parameters of every reaction to produce the solid, water, alipahtics, phenols, aromatic with a single ring aromatic non-phenol, heavy molecular weight compounds, and gas product.

At a temperature below $725 \mathrm{~K}$, the yield of the gas product was higher than that of the liquid products. This results from the swift split of the lignin chains that mainly produce water and/ or gas products. The estimated kinetic parameters showed that the rate of thermal cracking of lignin is higher than that of the liquid product, which points out that the possibility of secondary reactions is low. The formation of the ASR-Non-pH and aliphatics families is lower than that of the HMWC, which could originate from the complex structure of the lining.

A saddle reactor is developed, and good mixing was observed for 20-30 g of silica sand and speed mixing of 15-30 RPM.

\section{Author details}

Said Samih ${ }^{1,2}$, Sherif Farag ${ }^{1,3,4}$ and Jamal Chaouki ${ }^{1 *}$

*Address all correspondence to: jamal.chaouki@polymtl.ca

1 Department of Chemical Engineering, Process Engineering Advanced Research Lab (PEARL), Ecole Polytechnique de Montreal, Montréal, QC, Canada

2 AFMERICA TECHNOLOGY Inc., Corot, Verdun (QC), Canada

3 Faculty of Engineering at El-Mattaria, Helwan University, Cairo, Egypt

4 RMTech for Environmental Solutions Inc., Canada

\section{References}

[1] Samih S, Chaouki J. Development of a fluidized bed thermogravimetric analyzer (in English). Aiche Journal. Jan 2015;61:84-89

[2] Samih S, Chaouki J. Catalytic ash free coal gasification in a fluidized bed thermogravimetric analyzer. Powder Technology. Jul 1, 2017;316:551-559

[3] Samih S. Développement d'un analyseur thermogravimétrique à lit fluidisé : application à la gazéification catalytique du charbon. PhD Thesis, École Polytechnique de Montréal. 2016

[4] Samih S, Chaouki J. Coal Pyrolysis and Gasification in a Fluidized Bed TGA. The Canadian Journal of Chemical Engineering. 2018

[5] Process Engineering Advanced Research Lab (PEARL). Available: http://pearl.polymtl.ca/ 
[6] Kopyscinski J, Rahman M, Gupta R, Mims CA, Hill JM. $\mathrm{K}_{2} \mathrm{CO}_{3}$ catalyzed $\mathrm{CO}_{2}$ gasification of ash-free coal. Interactions of the catalyst with carbon in $\mathrm{N}_{2}$ and $\mathrm{CO}_{2}$ atmosphere. Fuel, vol. 117, Part B, pp. 1181-1189, 1/30/ 2014

[7] Okuyama N, Komatsu N, Shigehisa T, Kaneko T, Tsuruya S. Hyper-coal process to produce the ash-free coal. Fuel Processing Technology. 2004;85:947-967

[8] Farag S, Chaouki J. Economics evaluation for on-site pyrolysis of kraft lignin to valueadded chemicals. Bioresource Technology. 2015;175:254-261

[9] Farag S, Fu D, Jessop PG, Chaouki J. Detailed compositional analysis and structural investigation of a bio-oil from microwave pyrolysis of kraft lignin. Journal of Analytical and Applied Pyrolysis. 2014;109:249-257

[10] Farag S, Kouisni L, Chaouki J. Lumped Approach in Kinetic Modeling of Microwave Pyrolysis of Kraft Lignin. Energy \& Fuels. Feb 2014;28:1406-1417

[11] Fu D, Farag S, Chaouki J, Jessop PG. Extraction of phenols from lignin microwavepyrolysis oil using a switchable hydrophilicity solvent. Bioresource Technology. 2014; 154:101-108

[12] Mudraboyina BP, Farag S, Banerjee A, Chaouki J, Jessop PG. Supercritical fluid rectification of lignin pyrolysis oil methyl ether (LOME) and its use as a bio-derived aprotic solvent. Green Chemistry. 2016;18:2089-2094

[13] Farag S, Chaouki J. A modified microwave thermo-gravimetric-analyzer for kinetic purposes. Applied Thermal Engineering. 2015;75:65-72

[14] Farag S, Mudrabovina BP, Jessop PG, Chaouki J. Impact of the Heating Mechanism on the Yield and Composition of Bio-oil from Pyrolysis of Kraft Lignin. Biomass and Bioenergy. 2016

[15] Ebrahimpour O, Chaouki J, Dubois C. Diffusional effects for the oxidation of SiC powders in thermogravimetric analysis experiments (in English). Journal of Materials Science. 2013;48:4396-4407

[16] Lee JM, Kim YJ, Lee WJ, Kim SD. Coal-gasification kinetics derived from pyrolysis in a fluidized-bed reactor. Energy. 1998;23:475-488

[17] Hakeem AA, Mu L, Berger RJ, Kapteijn F, Makkee M. Kinetics of the high temperature water-gas shift over $\mathrm{Fe}_{2} \mathrm{O}_{3} / \mathrm{ZrO}_{2}, \mathrm{Rh} / \mathrm{ZrO}_{2}$ and $\mathrm{Rh} / \mathrm{Fe}_{2} \mathrm{O}_{3} / \mathrm{ZrO}_{2}$. Chemical Engineering Journal. 2015;263:427-34

[18] Wei J, Iglesia E. Structural requirements and reaction pathways in methane activation and chemical conversion catalyzed by rhodium. Journal of Catalysis. 2004;225:116-127

[19] Wang Y, Zhai Y, Pierre D, Flytzani-Stephanopoulos M. Silica-encapsulated platinum catalysts for the low-temperature water-gas shift reaction. Applied Catalysis B: Environmental. 2012;127:342-350

[20] Li S, Cheng Y. Catalytic gasification of gas-coal char in $\mathrm{CO}_{2}$. Fuel. 1995;74:456-458, 
[21] Adnadjevic BK. Jovanovic JD. A comparative kinetics study on the isothermal heterogeneous acid-catalyzed hydrolysis of sucrose under conventional and microwave heating. Journal of Molecular Catalysis A: Chemical. 2012;356:70-77

[22] Adnađević B, Gigov M, Sindjic M, Jovanović J. Comparative study on isothermal kinetics of fullerol formation under conventional and microwave heating. Chemical Engineering Journal. 2008;140:570-577

[23] Fukushima J, Kashimura K, Takayama S, Sato M, Sano S, Hayashi Y et al. In-situ kinetic study on non-thermal reduction reaction of $\mathrm{CuO}$ during microwave heating. Materials Letters. 2013;91:252-254

[24] Sun J, Wang W, Liu Z, Ma Q, Zhao C, Ma C. Kinetic Study of the Pyrolysis of Waste Printed Circuit Boards Subject to Conventional and Microwave Heating. Energies. 2012;5:3295-3306

[25] Chen F, Wang G, Shi C, Zhang Y, Zhang L, Li W et al. Kinetics of glycolysis of poly(ethylene terephthalate) under microwave irradiation. Journal of Applied Polymer Science. 2013;127: 2809-2815

[26] Yan W, Hu X, Zhang G, Deng M, Yi C, Xu Z. Microwave assisted preparation of monodisperse polymeric microspheres and its morphologies and kinetics. Journal of Wuhan University of Technology-Mater. Science Edition. vol. 27, pp. 1100-1104, 2012/12/01

[27] Adnadjević BK, Jovanović JD. Kinetics of Isothermal Ethanol Adsorption onto a Carbon Molecular Sieve under Conventional and Microwave Heating. Chemical Engineering \& Technology. 2012;35:761-768

[28] Li Z, Han L, Xiao W. Influence of microwave heating on the liquefaction kinetics of corn stover in ethylene glycol. BioResources. 2013;8:3453-3460

[29] Yadav GD, Borkar IV. Kinetic modeling of microwave-assisted chemoenzymatic epoxidation of styrene. AIChE Journal. 2006;52:1235-1247

[30] Mazo P, Estenoz D, Sponton M, Rios L. Kinetics of the transesterification of castor oil with maleic anhydride using conventional and microwave heating. Journal of the American Oil Chemists Society. 2012;89(7):1355-1361

[31] Farag S. Production of chemicals by microwave thermal treatment of lignin [Philosophiae Doctor Ph.D. Thesis] Chemical Engineering. University of Montreal: École Polytechnique de Montréal, December 2013

[32] Farag S, Sobhy A, Akyel C, Doucet J, Chaouki J. Temperature profile prediction within selected materials heated by microwaves at $2.45 \mathrm{GHz}$. Applied Thermal Engineering. 2012;36:360-369

[33] Doucet J, Laviolette J-P, Farag S, Chaouki J. Distributed microwave pyrolysis of domestic waste. Waste and Biomass Valorization. 2014;5(1):1-10 
